\title{
Interpreting the Significance of the Lagged Interest Rate in Estimated Monetary Policy Rules ${ }^{1}$
}

\author{
William B. English, \\ William R. Nelson, \\ and \\ Brian P. Sack \\ Division of Monetary Affairs \\ Board of Governors of the Federal Reserve System \\ Washington, DC 20551
}

April 24, 2002

\footnotetext{
${ }^{1}$ We thank Antulio Bomfim, Darrel Cohen, Refet Gurkaynak, Don Kohn, Athanasios Orphanides, Dave Reifschneider, and our colleagues in the Division of Monetary Affairs at the Federal Reserve Board for helpful comments. Joe Rosenberg provided excellent research assistance. The views expressed are those of the authors and do not represent the opinions of the Board of Governors of the Federal Reserve System or other members of its staff. Comments are welcome to william.b.english@frb.gov, william.r.nelson@frb.gov, or brian.p.sack@ frb.gov.
} 


\title{
Interpreting the Significance of the Lagged Interest Rate
}

\author{
in Estimated Monetary Policy Rules
}

\begin{abstract}
Many researchers have found that the lagged interest rate enters estimated monetary policy rules with overwhelming significance. However, a recent paper by Rudebusch (2002) argues that the lagged interest rate is not a fundamental component of the U.S. policy rule, and that its significance arises from the omission of serially correlated variables from the policy rule. This paper demonstrates that, contrary to Rudebusch's claims, these two hypotheses can be directly distinguished in the estimation of the policy rule. Our findings indicate that while serially correlated omitted variables may be present, the lagged interest rate enters the policy rule in its own right and plays an important role in describing the behavior of the federal funds rate.
\end{abstract}




\section{Introduction}

Over the past ten years there has been extensive research on the setting of monetary policy. One of the findings of this literature, and perhaps the one that sparked much of the subsequent research, is that monetary policy can be described to a large extent by simple policy rules that determine the short-term interest rate as a function of a small number of variables, such as the output gap and inflation. Taylor (1993) was among the first to reach this conclusion. Taylor's point was not that policymakers actually follow a simple policy rule or consider only a couple of variables in setting monetary policy. On the contrary, he argued that simple algebraic rules were unlikely to capture the complexities of the policy process. Nonetheless, he found that the results from that process could be well approximated by a fairly simple description of the short-term interest rate.

A large number of other researchers have subsequently refined this point. These papers have focused on estimating simple policy rules from realized data, rather than imposing the reaction coefficients assumed by Taylor, and on modifying the simple rule in various directions. But although the literature has arrived at many different specifications and estimates of simple policy rules, many of them find that the lagged interest rate enters the estimated policy rule with overwhelming significance. This finding is evident not only in the United States, as described by Sack (1998), Amato and Laubach (1999), and Clarida, Gali, and Gertler (2000), but also in a number of other industrial countries, as described by Goodhart (1997).

Although there is general agreement that the lagged interest rate is a significant variable in estimated policy rules, there is some debate about why this is the case. The presence of the lagged term tends to make the federal funds rate adjust sluggishly in response to changes in 
economic conditions, a factor that policymakers may find attractive for a number of reasons.

First, inertial policy, by influencing expectations of future policy movements, can allow the policymaker to exercise effective control of output and inflation without requiring aggressive movements in the short-term interest rate, as emphasized by Woodford (1999), Williams (1999), and Levin, Wieland, and Williams (1999). Second, inertial movements in the federal funds rate may be optimal in the presence of various uncertainties about the structure of the macroeconomic model, about the values of the parameters of the model, or about the quality of contemporaneous data releases. The effects of such uncertainties on optimal policy are examined in Sack (1998, 2000), Orphanides (1998), Rudebusch (2001), and Wieland (1998), among others. ${ }^{2}$ These arguments, and some of the relevant references, are summarized in more detail in Sack and Wieland (2000).

Rudebusch (2002), however, argues that the lagged interest rate may not enter the actual policy rule at all. Instead, he argues that the significance of the lagged interest rate in estimates of the policy rule may be attributed to serially correlated errors in the policy rule that correspond to the FOMC's reaction to other factors. As evidence, he points to the lack of predictive power of the term structure, arguing that federal funds rate movements should be predictable (and should be predicted by the term structure) if the coefficient on the lagged interest rate truly represented sluggish adjustment. Rudebusch concludes that "the lagged policy rate, though

\footnotetext{
${ }^{2}$ Many papers also assume that the policymaker's loss function contains a penalty for changes in the policy interest rate. While this is a convenient way to capture the smoothness of interest rate movements, the theoretical justification for the penalty is not clear. One possibility is a concern that large policy moves could, either by confusing market participants or by causing large movements in asset prices, have adverse effects on the operation of some financial markets. For example, at the February 1994 FOMC meeting, as the Committee was considering tightening after a long period of unchanged policy, Chairman Greenspan argued that a 25 basis point policy tightening was preferable to a 50 basis point tightening in part because the larger move had "a very high probability of cracking these [financial] markets" (FOMC Secretariat, 1994, p. 53).
} 
useful in mopping up residual serial correlation, should not be given a structural partial adjustment interpretation with regard to central bank behavior."

This paper attempts to answer the question of whether the lagged interest rate is a fundamental component of the policy rule estimated for the United States, or whether its significance can instead be attributed strictly to serially correlated errors. While the two alternatives both result in considerable inertia in interest rate movements, we demonstrate that there is a fundamental difference in their implications for the dynamics of the federal funds rate. This difference allows us to estimate a policy rule with both components and to test their significance and their relative importance in describing federal funds rate movements.

By relying on direct evidence from the estimated policy rule to distinguish between the hypotheses of partial adjustment and serially correlated errors, this paper does not have to resort to looking at indirect evidence from the term structure of interest rates, as in Rudebusch (2002). A direct test is preferable, since the lack of predictive power of market interest rates that Rudebusch finds might not speak at all to the difference between partial adjustment and serially correlated errors, but might arise because of well known violations of the assumptions underlying the expectations hypothesis. ${ }^{3}$

Overall, we do not disagree with the idea that various factors can push the federal funds rate away from the prescription of a simple policy rule for a time. Indeed, one would expect this to be the case since, as mentioned above, the simple policy rule is merely an approximation for

\footnotetext{
${ }^{3}$ Time variation in the term premium embedded in longer-term rates and various other factors can limit the predictive power of longer-term interest rates, even when movements in the short-term rate are predictable. Rudebusch allows for some variation in the term premium, but he imposes fairly strong assumptions about its behavior that are unlikely to hold in practice.
} 
the result of a complicated policy process. However, our results suggest that omitted factors cannot account for the bulk of the significance of the lagged interest rate in estimated policy rules. On the contrary, our results indicate that the lagged interest rate enters the policy rule in its own right and plays an important role in the dynamics of the federal funds rate.

\section{Two Models of the Federal Funds Rate}

We begin by comparing two specifications of a monetary policy rule: one in which the lagged interest rate enters, and one that does not include the lagged rate but allows serially correlated errors. The first of these two alternatives can be written as follows:

$$
\begin{aligned}
& \hat{i}_{t}=b_{0}+b_{\pi} \cdot \pi_{t}+b_{y} \cdot y_{t} \\
& i_{t}=(1-\lambda) \cdot \hat{i}_{t}+\lambda \cdot i_{t-1}+\varepsilon_{t},
\end{aligned}
$$

where $i$ is the federal funds rate, $\pi$ is the inflation rate, $y$ is the output gap, and $\varepsilon$ is an i.i.d error term. This specification has been termed a "partial adjustment" rule by some researchers, including Clarida, Gali, and Gertler (1999). The reason is that under this specification, the federal funds rate moves gradually toward the rate $\hat{i}$, closing $1-\lambda$ of the gap in each quarter $(\lambda$ is assumed to be less than one). However, it is worth noting that $\hat{i}$ (which we refer to as the "Taylor-rule rate") is not necessarily the desired level of the interest rate, and in fact the interest rate may never reach $\hat{i}$, as output and inflation may respond to the movement in the interest rate before $\hat{i}$ is reached. ${ }^{4}$ But a positive $\lambda$ does result in inertial movements in the federal funds rate

\footnotetext{
${ }^{4}$ Note that the "Taylor-rule rate" is not the rate that would be implied by Taylor's (1993) rule, but instead is that implied by a rule of the form assumed by Taylor with coefficients estimated based on the various specifications described in the text.
} 
in the direction of the Taylor-rule rate, and we will loosely refer to this as partial adjustment.

By comparison, a policy rule with serially correlated errors can be written as follows:

$$
\begin{aligned}
& \hat{i}_{t}=b_{0}+b_{\pi} \cdot \pi_{t}+b_{y} \cdot y_{t} \\
& i_{t}=\hat{i}_{t}+v_{t} \\
& v_{t}=\rho v_{t-1}+\varepsilon_{t},
\end{aligned}
$$

where $v$ is a serially correlated error term and the other variables are defined as in equation (1). Under this specification, there is no partial adjustment towards the Taylor-rule rate, and the funds rate deviates from the Taylor-rule rate only by the error term. Under Rudebusch's (2002) interpretation, this error term represents various episodic events that affect the federal funds rate but are not included in the Taylor rule specification, such as the credit crunch in the early 1990s or concerns about the seizing up of financial markets in the fall of $1998 .^{5}$ These errors are assumed to follow a first-order autoregressive process, so that a fraction $1-\rho$ of the difference $(v)$ between the federal funds rate and the Taylor-rule rate closes each quarter.

Nonlinear least squares estimates of the monetary policy rule under these two specifications are presented in the top panel of Table 1. The sample includes quarterly data from 1987Q1 to 2000Q4. The federal funds rate is defined as the average effective federal funds rate over the quarter, the output gap is based on real GDP relative to the CBO's estimate of potential GDP, and the inflation measure is the four-quarter change in the GDP deflator. ${ }^{6}$ First, note that the coefficients on the output gap and inflation are largely consistent with other estimates from

\footnotetext{
${ }^{5}$ For now, we assume that the innovation to the error term, $\varepsilon$, is i.i.d., consistent with Rudebusch (2002). We explore alternatives to this assumption below.

${ }^{6}$ The quarter-average funds rate is used to correspond with the observations for output and inflation, which are based on activity over the quarter. However, the findings regarding the relative importance of the parameters $\rho$ and $\lambda$ are robust to using the end-of-quarter target federal funds rate in the estimated rule.
} 
the literature, including a significant coefficient on the output gap and a coefficient on inflation that is greater than $1 .^{7}$ More importantly, note that both rules capture the inertial behavior of the federal funds rate, but in different ways - through a significant parameter $\lambda$ in equation (1), and through a significant parameter $\rho$ in equation $(2) .^{8}$

Similar results are found under forward-looking policy rules. It is commonly argued that monetary policy must be preemptive, which has led researchers to consider various policy rules that respond to forecasts of output and inflation. ${ }^{9}$ Rudebusch (2002) considers a rule in which the policymaker responds to the contemporaneous output gap and the anticipated inflation rate over the coming four quarters. Specifically, he replaces the first equations in (1) and (2) with a Taylor-rule rate determined by $\hat{i}_{t}=b_{0}+b_{\pi} \cdot E_{t-1} \pi_{t+4}+b_{y} \cdot E_{t-1} y_{t}$, where the policy decision at time $t$ is, by assumption, based on information available at time $t-1$. Under this specification, the two policy rules can be estimated using instrumental variables, where the instruments are based on information available at time $t-1 .^{10}$ The results, shown in the bottom panel of Table 1 , are broadly similar to those found with the backward-looking rules, with the parameters $\rho$ and $\lambda$ still estimated to be substantial and highly significant.

The difficulty in distinguishing between the hypotheses of partial adjustment and serially correlated errors, it has been argued, is that they have similar implications for the path of the

\footnotetext{
${ }^{7}$ Interestingly, under equation (2), we find that the coefficients on both output and inflation fall noticeably. Rudebusch (2002) finds similar results.

${ }^{8}$ If the federal funds rate affects the output gap or the inflation rate within the current quarter, then the estimation results reported here are potentially biased because the right-hand-side variables are correlated with the error term. However, the results are only little changed if the equation is estimated using instruments known at time $t$ - 1 , suggesting that such misspecification is not a problem.

${ }^{9}$ See, for example, Clarida, Gali, and Gertler (2000) and Orphanides (2001).

${ }^{10}$ The instruments we use are four lags each of inflation, the output gap, and the federal funds rate.
} 
short-term interest rate. Indeed, this is clearly the case for the dynamics of the funds rate in response to a gap between the interest rate and the Taylor-rule rate. In both cases, in the absence of new shocks, a fixed portion of the gap (either $1-\lambda$ or $1-\rho$ ) closes each period until the gap is eliminated. The similarity of the two specifications led Rudebusch (2002) to seek indirect evidence about the two hypotheses based on the term structure of interest rates.

We instead argue that the two hypotheses can be distinguished based on direct evidence from the estimation of the policy rule. In particular, the two specifications have very different implications for the response of the interest rate to changes in the Taylor-rule rate. To see that, note that manipulating the partial-adjustment specification in equation (1) yields

$$
\Delta i_{t}=(1-\lambda) \cdot \Delta \hat{i}_{t}+(1-\lambda) \cdot\left(\hat{i}_{t-1}-i_{t-1}\right)+\varepsilon_{t} .
$$

This equation indicates that the interest rate only partially adjusts to changes in the Taylor-rule rate as well as to the lagged difference between the Taylor-rule rate and the funds rate. Similar manipulation of the serially-correlated-error specification in equation (2) yields

$$
\Delta i_{t}=\Delta \hat{i}_{t}+(1-\rho) \cdot\left(\hat{i}_{t-1}-i_{t-1}\right)+\varepsilon_{t} .
$$

The second term of equation (4) is similar to that of equation (3)-the federal funds rate closes only a fraction of the lagged difference between the Taylor-rule rate and the actual rate. However, the first term in the two specifications differs importantly. In contrast to the partial adjustment case, the funds rate adjusts fully to changes in the Taylor-rule rate in the seriallycorrelated-error specification, as the serially correlated error maintains the gap between the 
federal funds rate and the new level of the Taylor-rule rate. ${ }^{11}$

The intuition for the distinction between the two specifications is simple. Even if the Federal Reserve is responding to some factor that causes its policy to deviate from the Taylorrule rate as in rule (4), it should still respond fully to any observable changes in output and inflation that shift the Taylor-rule rate. If the Federal Reserve instead follows a rule with some partial adjustment as in (3), it reacts slowly to all macroeconomic developments, including changes in the Taylor-rule rate.

Based on this difference between the two equations, we can test empirically to see which model is more consistent with the data. To do so, we use nonlinear least squares to estimate the change in the funds rate as a function of the change in the Taylor-rule rate and the lagged gap between the Taylor-rule rate and the funds rate. The results, which are shown in Table 2, can then be evaluated in light of equations (3) and (4). In the backward-looking version of the model, the coefficient multiplying the expected change in the Taylor-rule rate is well below 1 , consistent with the partial adjustment explanation of the significance of the lagged interest rate and inconsistent with the serially-correlated-error specification. Indeed, the hypothesis that the coefficient equals 1 is overwhelmingly rejected. Similar results are found under the forwardlooking specification of the rule.

Although the data appear more consistent with the partial-adjustment specification, the coefficient restriction in (3) — that the coefficient on the change in the Taylor-rule rate equals the

\footnotetext{
${ }^{11}$ Of course, the fact that equations (3) and (4) have the same form owes to the simple structures assumed in each case. For example, if the serially correlated errors had higher-order dynamics, then additional terms would be introduced into equation (4). Similarly, more complicated specifications of partial adjustment would affect equation (3). Nonetheless, the difference in the first terms of the equations, which is critical to distinguishing between the two hypotheses, would remain unaffected by these changes.
} 
coefficient on the policy gap—can be rejected at the 5 percent significance level in the backward-looking rule, although this constraint cannot be rejected at any conventional significance level in the forward-looking case. Thus, of the two hypotheses, the data seem to prefer partial adjustment to serially correlated errors, although the results are not perfectly consistent with the partial-adjustment specification above.

\section{Allowing Both Partial Adjustment and Serially Correlated Errors}

Although the data appear to be more consistent with partial adjustment, there is no reason to assume that only one of the two hypotheses holds. Indeed, both partial adjustment and serially correlated errors could be contributing to the significance of the lagged federal funds rate in estimates of monetary policy rules. The two hypotheses can be easily nested, as follows:

$$
\begin{aligned}
& \hat{i}_{t}=b_{0}+b_{\pi} \cdot \pi_{t}+b_{y} \cdot y_{t} \\
& i_{t}=(1-\lambda) \cdot \hat{i}_{t}+\lambda \cdot i_{t-1}+v_{t} \\
& v_{t}=\rho \cdot v_{t-1}+\varepsilon_{t},
\end{aligned}
$$

where, as above, $\lambda$ is the partial adjustment parameter, and $\rho$ is the serial correlation parameter.

In this case, the equation for the change in the funds rate becomes:

$$
\Delta i_{t}=(1-\lambda) \cdot \Delta \hat{i}_{t}+(1-\lambda)(1-\rho) \cdot\left(\hat{i}_{t-1}-i_{t-1}\right)+\lambda \rho \cdot \Delta i_{t-1}+\varepsilon_{t} .
$$

The first term captures the partial adjustment of the interest rate to the most recent change in the Taylor-rule rate; the remaining terms reflect the slow closing of any existing gap between the funds rate and the Taylor-rule rate and the consequent inertia of interest rate changes. Since $\lambda$ and $\rho$ enter these latter terms symmetrically, distinguishing between the two hypotheses still depends on the estimated response of the funds rate to changes in the Taylor-rule rate. Note that 
if $\lambda$ equals 0 , equation (6) reduces to the case of serially correlated errors (equation (4)) considered above, while if $\rho$ equals 0 , it reduces to the case of partial adjustment (equation (3)).

The results from estimating equation (6) are shown in the first column of Table 3. The estimates of $\lambda$ and $\rho$ are both highly significant under the backward- and forward-looking rule specifications, suggesting that both partial adjustment and serially correlated errors are present. ${ }^{12}$ Moreover, if we estimate equation (6) without imposing any restrictions on the coefficients, we cannot reject the restriction that the coefficients on the three variables on the right hand side of equation (6) are the given functions of just two parameters $(\lambda$ and $\rho$ ) at conventional significance levels. These results suggest that allowing for serially correlated errors does reduce the estimated degree of partial adjustment to some extent, but the effect is small, with the $\lambda$ parameter falling from 0.72 to 0.60 under the backward-looking rule and from 0.78 to 0.66 under the forward-looking rule.

By comparison, Rudebusch (2002) also nests the hypotheses of partial adjustment and serially correlated errors into a single equation and finds that he cannot distinguish between the two hypotheses. However, his empirical exercise differs from ours in that he allows either partial adjustment or serially correlated errors to be present, but not both. In particular, Rudebusch estimates an equation similar to (6), only he leaves off the last term in the equation (the regressor $\Delta i_{t-1}$ ) because he assumes that either $\lambda=0$ or $\rho=0 .{ }^{13}$ Once that term is included, it

\footnotetext{
${ }^{12}$ We employ a sample ending in 2000Q4 for the backward-looking rule so that the sample will be the same as for the forward-looking rule. If the sample used for the backward-looking rule is extended to 2001Q4, thereby adding four quarters during which policy was adjusted very rapidly relative to historical norms, the estimated value of $\lambda$ falls a bit, to 0.55 , while the estimated value of $\rho$ rises to 0.84 . Both coefficients remain strongly significant. ${ }^{13}$ Indeed, we can replicate Rudebusch's findings if we leave off the last term of equation (6). The other difference in the approach, that we use a differenced equation while he uses an equation specified in interest rate levels, has no
} 
becomes evident that both factors are significantly present in the estimated rule.

We can use our estimates of the policy rule (6) to gauge the relative importance of partial adjustment and serially correlated errors in explaining the departure of the federal funds rate from the Taylor-rule rate. To do so, we simulate the path of the federal funds rate under two counterfactual scenarios: one with no partial adjustment $(\lambda=0)$ and one with no serial correlation in the errors $(\rho=0)$. In the simulation exercises, we take as given the paths of output and inflation, the other parameters of the policy rule, and the series of innovations $\varepsilon$. Of course, the paths of output and inflation will depend on the parameters $\lambda$ and $\rho$, since those parameters affect the dynamics of the federal funds rate. A more precise decomposition would require a model of the determination of output and inflation, which we do not pursue here. Nevertheless, the decomposition presented may be suggestive of the relative importance of the different factors.

The results are best understood by first rearranging equation (6) to yield the interest rate gap, or the difference between the actual federal funds rate and the Taylor-rule rate:

$$
i_{t}-\hat{i}_{t}=\lambda \cdot\left(i_{t-1}-\hat{i}_{t}\right)+\rho \cdot v_{t-1}+\varepsilon_{t} .
$$

For simplicity, we focus only on the backward-looking specification. According to equation (7), if there were no partial adjustment, then the variance of the interest rate gap would be determined by the variance of the serially correlated errors, the second term, and the variance of the innovation, the third term. At first glance, it might appear that the remaining variance of the interest rate gap, reflecting the effects of the first term, captures the impact of partial adjustment.

effect on the estimated parameters. To be consistent across policy rules estimated in levels and differences, we report in the tables $\mathrm{R}^{2}$ statistics based on the level of the funds rate. 
However, things are not that simple, because this term is also affected by the interaction between the two components. In particular, for a given variance of the innovation, serial correlation of the errors increases the size of the gap between the lagged funds rate and the Taylor-rule rate, thereby boosting the effect of partial adjustment on the variance of the interest rate gap. By setting $\rho$ to zero, however, the simulation isolates the partial adjustment component of the variance of the interest rate gap (as the variance of the first term adjusts accordingly). The remainder of the variance of the interest rate gap owes to the interaction between the two factors.

The results of this decomposition, shown in Table 4, indicate that partial adjustment accounts for 36 percent of the variance of the deviation of the federal funds rate from the Taylorrule rate. By contrast, serially correlated errors only account for 15 percent. The results also indicate that the interaction between these two components importantly adds to the variance of the interest rate gap. Overall, our estimated parameters suggest that both serially correlated errors and partial adjustment are statistically significant, but, at least over our sample, partial adjustment appears to have been a more important factor in explaining deviations of the federal funds rate from the Taylor-rule rate. ${ }^{14}$

To assess the precision of our point estimate for the decomposition, we employ a bootstrap method that accounts for sampling error in the estimation of the parameters. The bootstrap approach is taken because the decomposition of the variance is a complicated function of the estimated regression parameters. We start by drawing 10,000 series of 56 values of $\varepsilon$ from

\footnotetext{
${ }^{14}$ However, the ranking of the importance of the two factors may not be very robust. As noted earlier, if the sample is extended to 2001Q4 for the backward-looking rule, the value of $\lambda$ falls and that of $\rho$ rises. With these alternative parameters, partial adjustment still accounts for about 25 percent of the variance in the difference between the funds rate and the Taylor-rule rate, but the share attributed to serial correlation rises to about 35 percent.
} 
the actual distribution of the estimated residuals. For each series of residuals, we then use our estimated parameters and the actual values of $\pi$ and $y$ to generate values for the interest rate. We then estimate the values of the parameters for each of the 10,000 samples and calculate the decomposition for each sample.

The resulting distributions of the shares of the variance accounted for by the partial adjustment terms and the serial correlation term are shown in Figure 1, along with the bootstrap distributions of the parameters $\lambda$ and $\rho{ }^{15}$ As is evident from the figure, there is a considerable amount of uncertainty about the share of the variance accounted for by partial adjustment, with the 95 percent confidence interval for the share ranging from 7 to 91 percent. Nonetheless, for these estimated parameter values, the partial adjustment component is more important than the serially correlated errors component in about three-quarters of the samples.

\section{Alternative Explanations}

The above results indicate that both partial adjustment and serially correlated errors are significant components of Federal Reserve behavior since the late 1980s, and that both play an important role in explaining deviations of the federal funds rate from the Taylor-rule rate. However, those results were derived under a particular model of the serially correlated errorsnamely, that the omitted variable is orthogonal to the other variables in the regression. This corresponds to the case that Rudebusch considers, in which the omitted variable is interpreted as representing episodic and unpredictable events. But it might also be useful to consider the

\footnotetext{
${ }^{15}$ There is some difference between the means of the distributions and the point estimates shown in Tables 1 and 2, suggesting that there may be small sample bias in the estimates of the shares or that the assumption that the errors are i.i.d. is not valid.
} 
robustness of the above findings to alternative specifications of the errors. ${ }^{16}$

The short answer to the question of robustness is that some specifications of the error term can surely generate a significant value of $\lambda$ even if there is no partial adjustment. Indeed, the difficulty in arguing against this alternative hypothesis is that an omitted variable with the right properties can generate almost any effect on the estimated coefficients. As a result, we will limit the scope of our analysis to several plausible specifications of the omitted variable and investigate whether, in those cases, one might find partial adjustment even when there is none.

One possibility that raises some concern is that the Taylor-rule rate may be a noisy estimate of the central bank's policy intentions. Recall from equations (3) and (4) that the hypotheses of partial adjustment and serially correlated errors are distinguished by the contemporaneous response of the federal funds rate to changes in the Taylor-rule rate, with the partial adjustment being identified by an estimated coefficient that is less than 1 . But if the Taylor-rule rate is measured with error, one might expect this coefficient to be biased downwards, thus giving the appearance of partial adjustment. Indeed, in Monte Carlo exercises we have been able to generate a positive and significant estimate for $\lambda$ even if the data is generated from a rule without partial adjustment $(\lambda=0)$ by assuming that the econometrician only observes a noisy measure of the true Taylor-rule rate, $\hat{i}^{*}=\hat{i}+\eta$, where the error term $\eta$ is assumed to be orthogonal to $\hat{i}$.

\footnotetext{
${ }^{16}$ We have also tested the robustness of our findings with respect to alternative measures of output and inflation. The main conclusions are unaffected by the use of core CPI or core PCE price indexes instead of the GDP deflator. They are also unchanged if one uses the unemployment rate rather than the output gap as the measure of resource use.
} 
This exercise highlights that the appearance of partial adjustment can arise when the measure of $\hat{i}$ contains elements to which the central bank does not actually respond. Note, however, that this is the reverse of the problem highlighted by Rudebusch (2002). Rudebusch considers the possibility that the measure $\hat{i}$ omits variables to which the central bank actually does respond, or $\hat{i}=\hat{i}^{*}+\eta$, where the error term $\eta$ is assumed to be orthogonal to the econometrician's estimate of the Taylor-rule rate, $\hat{i}^{*}$. In that case, the presence of the error term does not generate a misleading appearance of partial adjustment, but simply shows up as an autocorrelated error. Indeed, a straightforward Monte Carlo exercise confirms that the estimated $\lambda$ is not significantly positive in this case.

One can imagine a number of reasons why the measure of the Taylor-type rule used by the econometrician might contain measurement error. One possibility that seems particularly plausible is that the analysis uses data that were not available to policymakers at the time of their policy decisions. ${ }^{17}$ To address this issue, we re-estimate the backward-looking policy rule using the "real time" data set that is available from the Federal Reserve Bank of Philadelphia and explained in Croushore and Stark (2000). The database includes the released measures of GDP and the GDP deflator, from which we construct real-time measures of the output gap and inflation. ${ }^{18}$ Because these variables are released with a lag, the data used are the variables released during the given quarter but pertaining to the previous quarter.

The resulting estimates are shown in the top panel of Table 3. The most significant

\footnotetext{
${ }^{17}$ See Orphanides (2001) for an analysis of the implications of real-time data for estimating monetary policy rules. ${ }^{18}$ To construct an output gap measure, we fit a quadratic trend through the data available at each point in time, allowing for a break in the linear term in 1973Q1.
} 
finding is that both partial adjustment and serially correlated errors remain present in the estimated policy rule. Note, however, that the coefficients on the output gap and inflation are affected by the use of real-time data, with the coefficient on inflation falling well below $1 .{ }^{19}$ Orphanides (2001) finds a similar result in his analysis of the impact of real-time data on estimated policy rules. He argues that rules with forward-looking components are more plausible in the context of real-time data. To investigate this possibility, we also estimate a realtime version of our forward-looking policy rule based on the same real-time measure of the lagged output gap and real-time forecasts of inflation over the next four quarters prepared by Federal Reserve Board staff for the Federal Open Market Committee. ${ }^{20}$ The results, shown in the bottom panel, indicate that the estimated response of policy to the forecast of inflation is much stronger. ${ }^{21}$ More importantly, the estimated values of $\lambda$ and $\rho$ remain significantly positive.

Overall, the results indicate that the partial adjustment found in estimated policy rules does not appear to be driven by the use of data that was not available at the time of the policy decisions. However, a number of other considerations could give rise to the appearance of a positive $\lambda$. For example, the central bank might not respond to all of the components of output or inflation equally, which would create an errors-in-variables problem for $\hat{i}$. Alternatively, the responsiveness of the central bank's policy rule could have shifted over the sample, or the

\footnotetext{
${ }^{19}$ This finding might reflect that the Federal Reserve is responding to more timely inflation information than the lagged GDP deflator, including alternative inflation measures, data on factor prices, or forward-looking inflation measures from surveys.

${ }^{20}$ This data comes from a dataset of real-time Greenbook forecasts for output and inflation that the Federal Reserve Bank of Philadelphia also makes available. Orphanides' (2001) analysis is also based on these forecasts.

${ }^{21}$ For the forward-looking rule, our sample ends in 1995 since more recent data on Greenbook forecasts are not yet publicly available. The baseline results shown in the first column of the table are not greatly changed if the model is estimated over a sample ending in 1995.
} 
equilibrium federal funds rate in the policy rule could have varied over time. ${ }^{22}$ To be sure, we cannot rule out all of the possibilities that might lead to a positive $\lambda$. Nevertheless, the above discussion helps to clarify the situation that can lead to the appearance of partial adjustmenterror in the $\hat{i}$ equation-and indicates that one of the most plausible sources of that error-the dependence of policymakers on real-time data-does not appear to drive our results.

\section{Conclusions}

The analysis presented here highlights an important difference between the behavior of the federal funds rate under a policy rule with partial adjustment versus one with seriallycorrelated errors. This difference can be used as the basis for empirical tests to distinguish between the two hypotheses based directly on estimates of the monetary policy rule. The results indicate that the partial adjustment of the short-term interest rate to economic conditions is an important feature of Federal Reserve behavior. Indeed, this characteristic of the policy rule accounts for a considerable fraction of the deviations of the federal funds rate from the Taylorrule rate since 1987, at least under the specification considered.

The results also support the notion that the estimated policy rule omits serially correlated errors, which could reflect various episodic factors described in Rudebusch (2002). Indeed, we strongly agree with the view that the estimated policy rule is simply a rough approximation of

\footnotetext{
${ }^{22}$ Changes in the equilibrium funds rate are unlikely to generate a positive $\lambda$. If changes in the equilibrium funds rate are not correlated with inflation and the output gap, then the errors in the estimated Taylor-rule rate would not be correlated with the actual Taylor-rule rate, and, as noted earlier, the estimate of $\lambda$ would not be biased. Moreover, if the equilibrium funds rate were positively correlated with the output gap, which might seem most plausible, then the estimated value of $\lambda$ would be biased down, not up, thereby understating the degree of partial adjustment.
} 
policy decisions, and thus it would be surprising if it did not periodically miss important factors influencing policy decisions. Nevertheless, our results indicate that even allowing for serially correlated errors, the partial adjustment term in the estimated policy rule remains significant. In fact, the bulk of the partial adjustment found in monetary policy rules remains even once serially correlated errors are permitted.

\section{References}

Amato, Jeffrey and Thomas Laubach (1999), The Value of Interest Rate Smoothing: How the Private Sector Helps the Federal Reserve, Economic Review, Federal Reserve Bank of Kansas City, 47-64.

Clarida, Richard, Jordi Gali, and Mark Gertler (2000), Monetary Policy Rules and Macroeconomic Stability: Evidence and Some Theory, Quarterly Journal of Economics 115, $147-180$.

Croushore, Dean and Tom Stark (2000), A Real-Time Data Set for Macroeconomists: Does Data Vintage Matter for Forecasting? Working Paper \#00-6, Federal Reserve Bank of Philadelphia.

FOMC Secretariat (1994), Transcript: Federal Open Market Committee Meeting, February 3-4, 1994. Mimeo., Board of Governors of the Federal Reserve System (available on the Board web site at http://www.federalreserve.gov/fomc/transcripts/1994).

Goodhart, Charles (1997), Why Do the Monetary Authorities Smooth Interest Rates? In European Monetary Policy (S. Collignon, ed.), London: Pinter, 119-174. 
Levin, Andy, Volker Wieland, and John Williams (1999), The Robustness of Simple Monetary Policy Rules Under Model Uncertainty, in Monetary Policy Rules (J. B. Taylor, ed.), Chicago: NBER and Chicago Press.

Orphanides, Athanasios (1998), Monetary Policy Evaluation with Noisy Information, Finance and Economics Discussion Series Working Paper \#1998-50, Board of Governors of the Federal Reserve System.

Orphanides, Athanasios (2001), Monetary Policy Rules Based on Real-Time Data, American Economic Review 91, 964-985.

Rudebusch, Glenn (2001), Is the Fed Too Timid? Monetary Policy in an Uncertain World, Review of Economics and Statistics 83, 203-217.

Rudebusch, Glenn (2002), Term Structure Evidence on Interest Rate Smoothing and Monetary Policy Inertia, forthcoming, Journal of Monetary Economics.

Sack, Brian (1998), Uncertainty, Learning, and Gradual Monetary Policy, Finance and Economics Discussion Series Working Paper \#1998-34, Board of Governors of the Federal Reserve System.

Sack, Brian (2000), Does the Fed Act Gradually? A VAR Analysis, Journal of Monetary Economics 46, 229-256.

Sack, Brian and Volker Wieland (2000), Interest Rate Smoothing and Optimal Monetary Policy: A Review of Recent Empirical Evidence, Journal of Economics and Business 52, 205-228.

Taylor, John (1993), Discretion versus Policy Rules in Practice, Carnegie-Rochester Conference Series on Public Policy 39, 195-214. 
Wieland, Volker (1998), Monetary Policy and Uncertainty about the Natural Unemployment Rate, Finance and Economics Discussion Series Working Paper \#1998-22, Board of Governors of the Federal Reserve System.

Williams, John (1999), Simple Rules for Monetary Policy, Finance and Economics Discussion Series Working Paper \#1999-12, Board of Governors of the Federal Reserve System.

Woodford, Michael (1999), Optimal Monetary Policy Inertia, mimeo, Princeton University. 
Table 1: Estimated Monetary Policy Rules Allowing Either Partial Adjustment or Serially Correlated Errors

\begin{tabular}{ccc}
\hline Coefficient & Eqn. (1) & Eqn. (2) \\
\hline \multirow{3}{*}{ Backward-looking Policy Rules: } & \\
$b_{0}$ & 2.10 & \\
& $(3.18)$ & 2.89 \\
$b_{\pi}$ & 1.56 & $(3.34)$ \\
& $(6.01)$ & 1.10 \\
$b_{y}$ & 0.93 & $(4.79)$ \\
$\lambda$ & $(7.27)$ & 0.28 \\
$\lambda$ & 0.72 & $(2.56)$ \\
& $(12.05)$ & - \\
$\rho$ & - & 0.92 \\
$R^{2}$ & 0.96 & $(16.61)$ \\
\end{tabular}

Forward-looking Policy Rules:

$\begin{array}{ccc}b_{0} & 2.01 & 0.86 \\ & (1.48) & (0.33) \\ b_{\pi} & 1.63 & 2.07 \\ & (3.16) & (1.93) \\ b_{y} & 0.81 & 0.54 \\ & (3.73) & (2.24) \\ \lambda & 0.78 & - \\ & (10.92) & 0.74 \\ & - & (5.37) \\ R^{2} & & 0.82\end{array}$

Estimates of the policy rules shown by equation number from the text. All rules estimated using quarterly data from 1987Q1 to 2000Q4. T-statistics shown in parentheses are corrected for heteroskedasticity and serial correlation. Instruments used for the forward-looking rules are four lags each of the federal funds rate, inflation, and the output gap. To be consistent across policy rules estimated in levels and differences, all $\mathrm{R}^{2}$ statistics are reported for the level of the funds rate. 


\section{Table 2: Estimated Monetary Policy Rules Used to Test between Partial Adjustment and Serially Correlated Errors}

\begin{tabular}{cc}
\hline Coefficient & $\begin{array}{c}\text { Eqns. (3 and 4) } \\
\text { (Unconstrained) }\end{array}$ \\
\hline Backward-looking Policy Rule: & \\
$b_{0}$ & 1.79 \\
& $(2.52)$ \\
$b_{\pi}$ & 1.66 \\
& $(6.05)$ \\
$b_{y}$ & 0.88 \\
& $(5.77)$ \\
Coef. on $\Delta \hat{i}_{t}$ & 0.42 \\
& $(4.39)$ \\
Coef. on $\left(\hat{i}_{t-1}-i_{t-1}\right)$ & 0.22 \\
& $(4.21)$ \\
$R^{2}$ & 0.96
\end{tabular}

Forward-looking Policy Rule:

$\begin{array}{cc}b_{0} & 0.81 \\ & (0.28) \\ b_{\pi} & 2.10 \\ & (1.84) \\ b_{y} & 0.85 \\ & (2.75)\end{array}$

Coef. on $\Delta \hat{i}_{t} \quad 0.38$

Coef. on $\left(\hat{i}_{t-1}-i_{t-1}\right) \quad 0.19$

$R^{2} \quad 0.93$

Estimates of policy rules of the form shown in equations (3) and (4), without the restrictions on the coefficients on $\Delta \hat{i}_{t}$ and $\left(\hat{i}_{t-1}-i_{t-1}\right)$. All rules estimated using quarterly data from 1987Q1 to 2000Q4. $\mathrm{T}$-statistics shown in parentheses are corrected for heteroskedasticity and serial correlation. Instruments used for the forward-looking rules are four lags each of the federal funds rate, inflation, and the output gap. To be consistent across policy rules estimated in levels and differences, all $\mathrm{R}^{2}$ statistics are reported for the level of the funds rate. 


\section{Table 3: Estimated Monetary Policy Rules Allowing Both Partial Adjustment and Serially Correlated Errors}

\begin{tabular}{ccc}
\hline Coefficient & Eqn. (6) & $\begin{array}{c}\text { Eqn. (6) wit } \\
\text { Real-Time }\end{array}$ \\
\hline \multirow{2}{*}{ Backward-looking Policy Rules: } & \\
$b_{0}$ & 1.87 & 4.07 \\
& $(2.50)$ & $(5.51)$ \\
$b_{\pi}$ & 1.60 & 0.40 \\
& $(5.66)$ & $(1.30)$ \\
$b_{y}$ & 0.72 & 0.85 \\
& $(4.65)$ & $(5.02)$ \\
$\lambda$ & 0.60 & 0.72 \\
& $(6.08)$ & $(7.55)$ \\
$\rho$ & 0.62 & 0.43 \\
& $(4.87)$ & $(3.97)$ \\
$R^{2}$ & 0.97 & 0.97
\end{tabular}

Forward-looking Policy Rules:

$\begin{array}{ccc}b_{0} & -0.83 & 1.82 \\ & (-0.20) & (2.29) \\ b_{\pi} & 2.71 & 1.13 \\ & (1.61) & (4.12) \\ b_{y} & 0.66 & 0.66 \\ & (2.39) & (6.27) \\ \lambda & 0.66 & 0.54 \\ & (4.06) & (6.34) \\ \rho & 0.67 & 0.47 \\ & (2.87) & (3.45) \\ R^{2} & 0.94 & 0.98\end{array}$

Estimates of the policy rules shown by equation number from the text. All rules estimated using quarterly data from 1987Q1 to 2000Q4. T-statistics shown in parentheses are corrected for heteroskedasticity and serial correlation. Instruments used for the forward-looking rule in column (1) are four lags each of the federal funds rate, inflation, and the output gap. For a description of the forward-looking rule in column (2), see the text. To be consistent across policy rules estimated in levels and differences, all $\mathrm{R}^{2}$ statistics are reported for the level of the funds rate. 
Table 4: Variance Decomposition of Deviations of the Interest Rate from the Taylor-Rule Rate

\begin{tabular}{lc}
\hline Source & Estimated Share \\
\hline Partial Adjustment & 36.1 \\
Serially Correlated Errors & 14.8 \\
Cross Terms & 33.8 \\
Contemporaneous Error & 15.4 \\
\multicolumn{1}{c}{ Total } & 100.0 \\
\hline $\begin{array}{l}\text { Decomposition is based on backward-looking policy rule (6) } \\
\text { from Table 3. For a description, see the text. Total does not sum } \\
\text { due to rounding. }\end{array}$
\end{tabular}



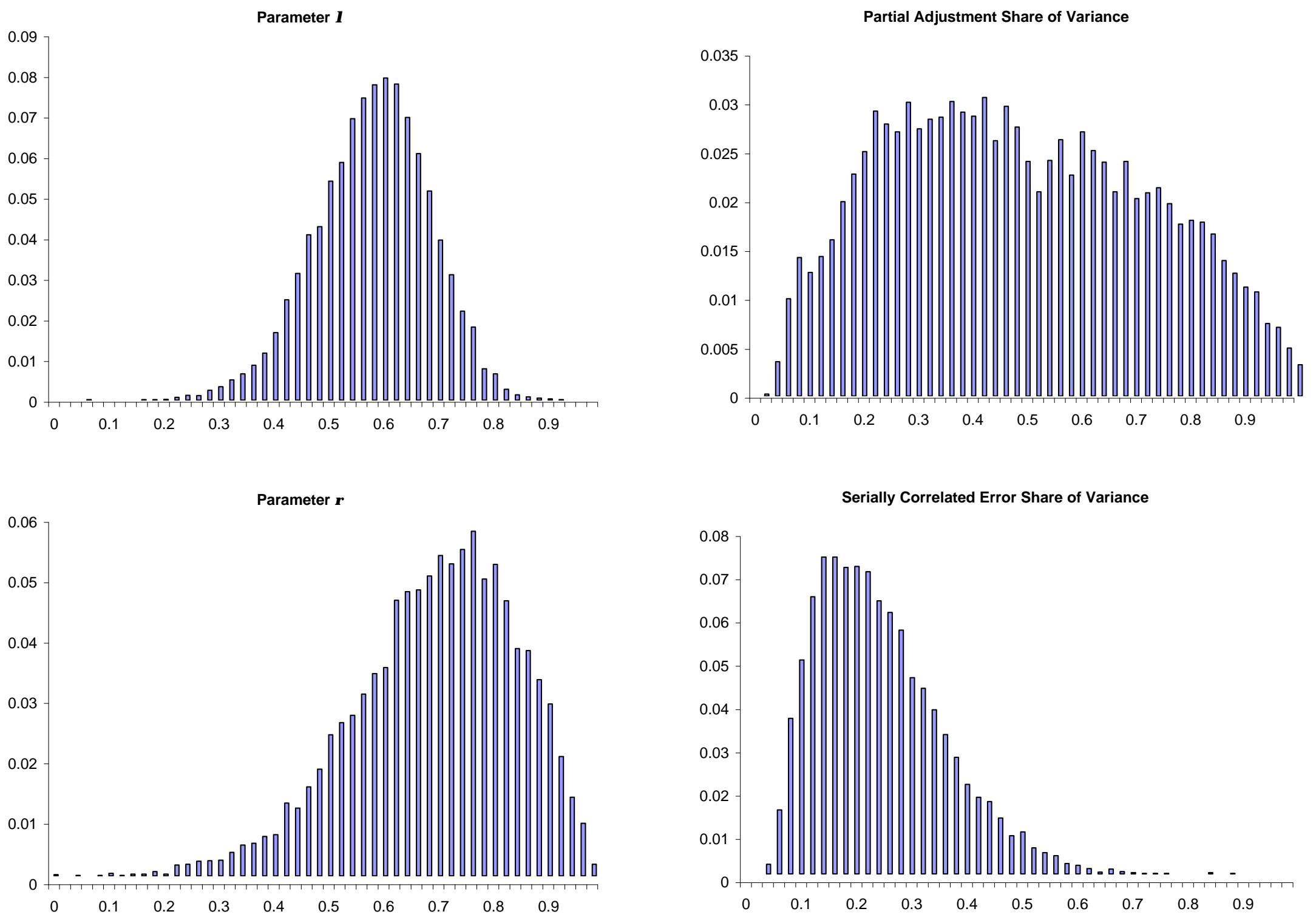

Serially Correlated Error Share of Variance

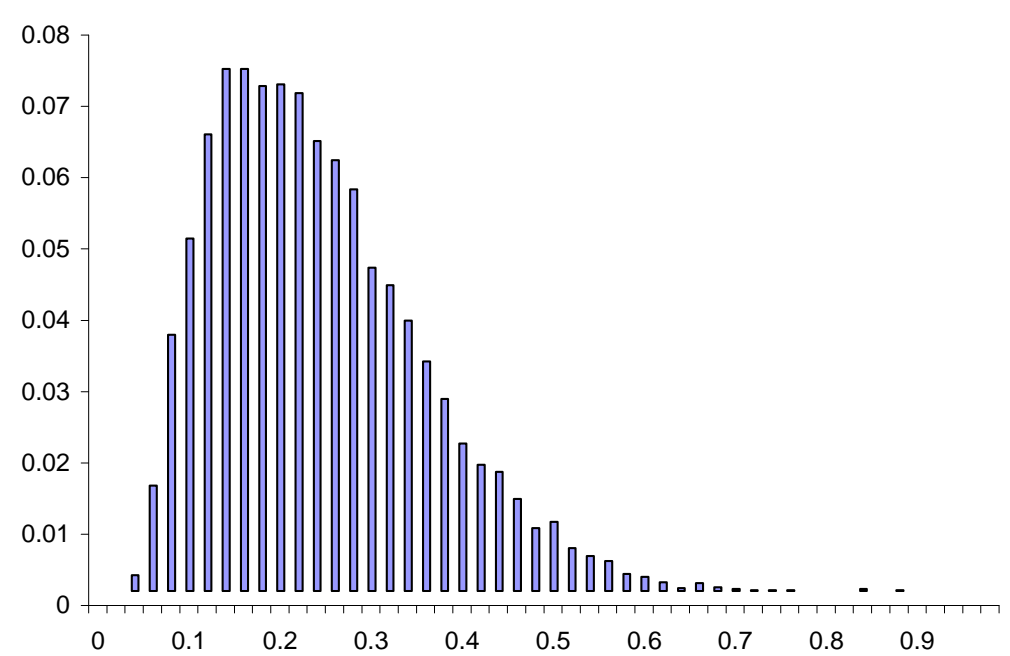

